\title{
Using an innovative journal club strategy to teach civility to nursing students: Lessons learned
}

\author{
Sheryl H. Jenkins, Wendy M. Woith, Deborah A. Stenger, Cindy S. Kerber \\ Mennonite College of Nursing at Illinois State University, Normal, Illinois, the United States. \\ Correspondence: Sheryl J enkins, Mennonite College of Nursing at I llinois State University, Normal, I L, the United States. \\ Email: sjenkin@ilstu.edu
}

Received: September 24, 2013

Accepted: October 16, $2013 \quad$ Online Published: November 18, 2013

DOI : 10.5430/jnep.v4n3p161

URL: http://dx.doi.org/10.5430/jnep.v4n3p161

\begin{abstract}
Background: Civility is foundational to nursing practice, crucial for nurse retention and productivity, and contributes to positive patient outcomes. Incivility in nursing begins in academia; nurse faculty have described uncivil behavior as a widespread problem among students. The purpose of this article is to describe an educational strategy to promote civility among nursing students in an academic setting.
\end{abstract}

Educational Innovation: We used a journal club intervention with seventy-nine senior nursing students. The intervention combined class discussions, speaker presentations, and active learning strategies to raise student awareness and effect positive behavioral change in senior students enrolled in a nursing leadership course during their final semester in the program. Six fifty-minute sessions were incorporated into course content. Each session included faculty-led discussion based on assigned journal articles and a variety of active learning strategies.

Lessons Learned: This article provides a description of each session and describes approaches we found helpful in implementing the journal club. We offer suggestions for tailoring a journal club strategy for use in a variety of ways in order to help nursing students make the transition from civility in school to civility in the workplace.

\section{Key words}

Civility, Nursing students, Journal clubs, Education

\section{Introduction}

In order to provide excellent patient care in today's complex healthcare environment, nurses must be able to act independently and collaborate with other professionals. Effective teams communicate and negotiate an atmosphere of respect, collegiality, and civility ${ }^{[1]}$. Therefore, civility is crucial to positive outcomes for nurses and patients ${ }^{[2]}$. Civility is foundational to nursing practice, and involves mutual respect, caring, relationship building, and collaboration ${ }^{[1-4]}$. Conversely, incivility contributes to poor outcomes for nurses and patients and is detrimental to healthcare ${ }^{[2]}$. Because incivility is also evident among nursing students, it is prudent to intervene during undergraduate education. The purpose of this article is to describe an innovative educational approach to promote civility among nursing students using a journal club format. 


\subsection{Background}

When the recipient of an act of incivility retaliates, a cycle of maladaptive behavior begins which can escalate into increasingly negative responses ${ }^{[5]}$. This interaction may ultimately end in a more violent physical exchange. Preventing incivility or enabling nurses to more effectively manage responses to uncivil behavior can result in departure from the incivility spiral.

\subsubsection{The impact of incivility}

Nurses have been subjected to many varied acts of incivility, including unfair criticism, caustic remarks, and sabotage ${ }^{[6-8]}$. This atmosphere of incivility contributes to nurse burnout and absenteeism, which decreases retention and productivity ${ }^{[1,6,7,9-11]}$. Nurses who resigned from clinical nursing cited the lack of support from peers as the most important factor in their decision to leave the bedside ${ }^{[8]}$. New graduate nurses, who are unfamiliar with their environment and dependent on the help of colleagues, may be vulnerable to unfriendly, unsupportive workplaces and are especially at risk for bullying ${ }^{[6-8,10]}$. Stressful, antagonistic work environments may contribute to poor patient outcomes ${ }^{[1,6,7,9]}$. For example, although newer technologies for identifying medication errors are becoming more common, nurses' self-report is still the primary way these errors are uncovered ${ }^{[9]}$. In one study, nurses failed to consult their peers and report medication errors for fear that they would be subject to rude comments, ridicule, exclusion, gossip, or punishment on their nursing unit. Unless they could depend on respectful treatment from their colleagues, these nurses failed to report even serious mistakes [9].

\subsubsection{I ncivility and nursing education}

Incivility in nursing begins in academia; nurse researchers have described uncivil behavior as a widespread problem among students ${ }^{[12,13]}$. In a pilot study, Jenkins and colleagues reported students identified overtly rude behaviors among their peers, such as eye-rolling, snickering, and talking while others were speaking ${ }^{[3]}$. Students have also described an atmosphere of academic competition in which peers refused to help others study and intentionally provided them with erroneous information ${ }^{[14]}$. Incivility is a significant problem in clinical settings as well; students have reported being ignored and treated unfairly by hospital nurses ${ }^{[15]}$. Nurse educators have developed interventions to reduce incivility among nursing students, including posting codes of conduct, clarifying behavioral expectations in classroom and clinical settings, and role modeling ${ }^{[3,4,12]}$. However, only two studies were found describing journal clubs as a means to encourage civility ${ }^{[3,4]}$.

Journal clubs have been used to broaden nurses' awareness of research ${ }^{[16,17]}$, evaluate policies and practices in light of evidence, encourage communication between shifts ${ }^{[17]}$, and achieve Magnet designation ${ }^{[16]}$. Journal clubs may involve discussion of the literature, speaker presentations, or a combination of the two ${ }^{[3,18]}$; they may occur face to face, on-line, or via teleconferencing ${ }^{[18]}$. We used a journal club intervention, which combined class discussions, speaker presentations, and active learning strategies to raise student awareness and effect positive behavioral change.

\section{Educational innovation}

\subsection{Learning environment}

We implemented a civility journal club intervention with seventy-nine senior students enrolled in a nursing leadership course during their final semester in our baccalaureate nursing program. The fifty-minute journal club sessions were incorporated into six regular class sessions and built on content provided in those sessions. Each session included faculty-led discussion based on assigned readings and a variety of active learning activities. This was an early morning class, so faculty used grant money to provide coffee and bagels for the students.

\subsection{I mplementation of the civility journal club}

The first session involved pre-intervention assessments of participants' perceptions of civility and academic integrity, and an evaluation of their coping skills. Students completed the Nurses' Intervention for Civility Education Questionnaire 
(NICE-Q), a four-point Likert-type survey developed by the faculty. The NICE-Q examines six aspects of civility: awareness of incivility, role modeling civil behavior, accepting others, refusing to participate in incivility, helpfulness, and academic dishonesty ${ }^{[4]}$. Participants then completed the Ways of Coping Questionnaire (WCQ) ${ }^{[19]}$. This four-point Likert-type scale was used to explore participants' responses to stressful situations and identify the coping strategies they used most often. Instrument reliability is reported elsewhere ${ }^{[19]}$.

As students submitted their completed surveys, the faculty collecting the documents did not make eye contact with students or thank them. Furthermore, students were allowed to overhear the faculty making disparaging comments about a third instructor who was "late" to the session. Students were next allotted 15 minutes to read an article on civility in nursing education. Once students had completed the article, they were asked to discuss what they thought and how they felt when faculty ignored them and gossiped about a colleague. Students stated they were very upset with the faculty and that their behavior was unprofessional. Students broke into small groups and discussed strategies for changing uncivil behavior. Each small group summarized their discussion to the class. The session concluded with a vigorous discussion about how students treat each other and strategies for change.

Prior to the second session, students were to have read an article on breathing techniques to manage stress. The session began with a discussion of the multiple stressors experienced by nursing students and how this stress may serve as an impetus for incivility. Students described the ways in which they coped with daily pressures and uncomfortable emotions. The discussion leader, a mental health advanced practice nurse, discussed a variety of stress-reduction techniques. She then led students through a breathing exercise designed to promote relaxation.

Burnout was the topic of session three. Students read an article on the importance of civility and healthy work environments in preventing burnout among new nurses. The class discussed the ways in which uncivil academic environments contribute to burnout among students. They brainstormed strategies for promoting civility among their peers. Students acknowledged the competitive nature of nursing education and suggested emphasizing teamwork and inclusivity. Since clinical groups can become exclusive, students recommended getting to know other students by inviting them to join study sessions and social activities. Other suggestions provided by students included offering positive feedback for desirable behavior, helping others with clinical assignments, and showing respect for peers and instructors during classroom interactions. They acknowledged that students sometimes need to vent frustrations, but suggested ending these conversations on a positive note.

Session four focused on lateral violence among students in the clinical setting. Students were asked to read an article on the topic. A faculty member with mental health expertise led the session. She divided the class into groups of nine or ten students and assigned each group to role-play the management of lateral violence. Scenarios involved snide remarks, being unavailable to peers, withholding information, deliberately setting up peers to fail, scapegoating, and breaking confidences. One group demonstrated ways in which to respond to non-verbal aggression. In this scenario, two students disagreed and one rolled her eyes. The recipient of the uncivil behavior said, "I sense there is something you want to say to me. It is okay to speak directly to me.” The students pointed out that lateral violence should be addressed directly in order to curtail the behavior.

The topic for the fifth session was academic dishonesty, which nursing students have described as a common uncivil behavior ${ }^{[14]}$. For this session, students were assigned four articles and asked to select two for discussion. These four articles were selected because they approached academic integrity from different perspectives. Initially, students were asked to talk about what they thought constituted cheating. Next, faculty led students in a discussion of academic integrity based on the readings. After the discussion, students divided into small groups to work on a case study. Each small group selected a note-taker and spokesperson who presented their ideas to the class. Interspersed throughout the session, students were shown YouTube video clips of other college students demonstrating various methods for classroom cheating.

The final journal club session focused on bullying in the workplace. Students were assigned topical reading prior to the session. The facilitator showed YouTube video-clips of nurses being bullied by other nurses. After each video-clip, the 
students discussed what they had seen, how they would have felt, and ways they could have managed the situation. Students concluded that bullying thrives in secret; they recommended immediately and openly confronting any act of aggression. This session concluded with post-intervention evaluations of participants' perceptions of civility and academic integrity, and an evaluation of their coping skills. They completed versions of the NICE-Q and WCQ that were identical to the pre-intervention tests, except that the NICE-Q post-test included a question asking students how participation in the CJC had impacted their behavior.

\section{Lessons learned}

\subsection{Approach}

The findings of our study are discussed in detail in Kerber and colleagues ${ }^{[4]}$. Our participants rated the experience very positively and recommended incorporation of the CJC into the nursing curriculum. We found that after completing the intervention, students were more aware of the impact of their own civil and uncivil acts; they reported being more helpful to peers; finally, they identified a broader array of effective coping skills for dealing with incivility.

Nurse educators are charged with conveying a large amount of nursing content within allotted class time, so it may be difficult for them to devote six hours of that time to a CJC. We offer the following recommendations for integrating a CJC into the classroom.

- Choose a course whose objectives fit well with the objectives of the CJC. We selected leadership because, in our program, the civility content coincided very closely with the course objectives. However, there are other courses that would be well suited for this topic and we suggest consideration of courses such as nursing trends and issues or mental health nursing.

- Our participants described the CJC as a valuable experience, and many recommended it be incorporated into a first semester course in order to have a greater impact on students over time.

- Exam times are undoubtedly stressful for students and students in our study recognized that academic stress contributes to incivility. Students often have difficulty focusing on traditional lecture content immediately following an exam, and as exams seldom take the entire class period, this may be an especially suitable time to schedule the CJC. Students may also have a raised awareness of the potential for incivility during the time following exams, and the more relaxed and open format of the CJC may ease tensions and facilitate learning.

- We offered six 50-minute CJC sessions over one semester, but the format of this intervention is flexible and can be tailored to fit the desired course. Educators may wish to design longer sessions to be offered less frequently; or they may schedule interventions over two consecutive semesters. Similarly, CJC sessions could be shortened and offered more frequently.

- At the end of the semester, speakers developed exam questions based on the CJC content they presented. These multiple-choice questions were incorporated into the students' comprehensive final exam. This served as a summative evaluation of their knowledge of content covered in the CJC.

\subsection{I mplementation strategies}

There are a variety of ways to implement CJCs. We found the following strategies especially helpful.

- Students told us repeatedly, verbally and in written evaluations, that they appreciated the bagels and coffee. They said it contributed to a more relaxed and pleasant atmosphere. We explained to students that the offering of food 
and drink was intended to express our appreciation for their participation and acknowledge their importance in contributing to the civility dialog.

- The CJC facilitators typically required students to read a civility-related article and discuss its' implications for nursing. We provided a variety of learning activities designed to enhance insight and deepen students' understanding of the concepts. This format allowed us to both teach and evaluate the impact of our teaching on students.

- Our CJC involved 79 students and three faculty facilitators, as well as a guest presenter. While our students typically stayed on topic, in large classes, instructors might wish to assign student leaders to small groups to keep conversation appropriately focused. Assigning a clinical group of eight or nine students to serve as facilitators for a session aided faculty in managing the activities and increased student facilitators’ involvement.

\section{Next steps}

The CJC was successful in promoting civility among nursing students and we plan to continue its use. In the next iteration of our CJC, we will provide three sessions to students in their first semester of the nursing program and three sessions during their last semester. This approach will allow us to use the first three sessions to raise awareness and promote strategies early in their careers that can be built on during the remaining program. The final three sessions during leadership will focus on vertical violence, lateral violence, and burnout, and help them make the transition from civility in school to civility in the workplace. We found the CJC to be a helpful strategy for raising civility awareness, increasing helpfulness, and expanding students' ability to cope when confronted with uncivil behaviors.

\section{References}

[1] Lindy C, Schaefer F. Negative workplace behaviours: An ethical dilemma for nurse managers. Journal of Nursing Management. 2010; 18: 285-292. PMid:20546468 http://dx.doi.org/10.1111/j.1365-2834.2010.01080.x

[2] American Association of Colleges of Nursing. The essentials of baccalaureate education for professional nursing practice. 2008. Available from: www.aacn.nche.edu/education-resources/baccessentials08.pdf. (12 November 2013, date last accessed).

[3] Jenkins S, Kerber C, Woith W. An intervention to promote civility among nursing students. Nursing Education Perspectives. 2013; 34: 95-100. http://dx.doi.org/10.5480/1536-5026-34.2.95

[4] Kerber C, Woith W, Jenkins S, Kim MJ. Journal clubs: A strategy to teach civility to nursing students. Journal of Nursing Education. 2012; 5: 277-282. PMid:22432534 http://dx.doi.org/10.3928/01484834-20120323-02

[5] Andersson L, Pearson C. Tit for tat? The spiraling effect of incivility in the workplace. Academy of Management Review. 1999; 24: 452-471.

[6] Cleary M, Hunt G, Walter G, Robertson M. Dealing with bullying in the workplace: Toward zero tolerance. Journal of Psychosocial Nursing. 2009; 47(12): 34-41.

[7] Johnston M, Phanhtharath P, Jackson B. The bullying aspect of workplace violence in nursing. JONA'S Healthcare Law, Ethics, and Regulation. 2010; 12(2): 36-42. PMid:20505478 http://dx.doi.org/10.1097/NHL.0b013e3181e6bd19

[8] MacKusick CI, Minick P. Why are nurses leaving? Findings from an initial qualitative study on nursing attrition. Med Surg Nursing. 2010; 19: 335-340. PMid:21337990

[9] Covell CL. Can civility in nursing work environments improve medication safety? Journal of Nursing Administration. 2010; 40: 300-301. PMid:20661058 http://dx.doi.org/10.1097/NNA.0b013e3181e93733

[10] Laschinger HKS, Grau AL, Finegan J, Wilk P. New graduate nurses’ experiences of bullying and burnout in hospital settings. Journal of Advanced Nursing. 2010; 66: 2732-2742. PMid:20722806 http://dx.doi.org/10.1111/j.1365-2648.2010.05420.x

[11] Lewis PS, Melacha A. The impact of workplace incivility on the work environment, manager, skill, and productivity. The Journal of Nursing Administration. 2011; 41: 41-47. PMid:21157243 http://dx.doi.org/10.1097/NNA.0b013e3182002a4c

[12] Clark CM. Faculty and student assessment of and experience with incivility in nursing education. Journal of Nursing Education. 2008; 46: 458-465. http://dx.doi.org/10.3928/01484834-20081001-03 
[13] Clark CM, Springer PJ. Incivility in nursing education: A descriptive study of definitions and prevalence. Journal of Nursing Education. 2007; 46: 7-14. PMid:17302094

[14] Woith W, Jenkins SD, Kerber C. Perceptions of academic integrity among nursing students. Nursing Forum. 2012; 47: 253-259. PMid:23127239 http://dx.doi.org/10.1111/j.1744-6198.2012.00274.x

[15] Thomas SP, Burk R. Junior nursing students’ experiences of vertical violence during clinical rotations. Nursing Outlook. 2009; 57: 226-231. PMid:19631065 http://dx.doi.org/10.1016/j.outlook.2008.08.004

[16] Steele-Moses SK. Developing a journal club at your institution. Clinical Journal of Oncology Nursing. 2009; $13(1): 109-112$. PMid:19193557 http://dx.doi.org/10.1188/09.CJON.109-112

[17] Stewart C, Snyder K, Sullivan SC. Journal clubs on the night shift: A staff nurse initiative. MEDSURG Nursing. 2010; 19(5): 305-306. PMid:21189746

[18] Silversides A. Journal clubs: A forum for discussion and professional development. Canadian Nurse. 2011; 107(2): 12-23.

[19] Folkman S, Lazarus R. Ways of coping questionnaire. 1998. Consulting Psychologists Press: Menlo Park, CA. 